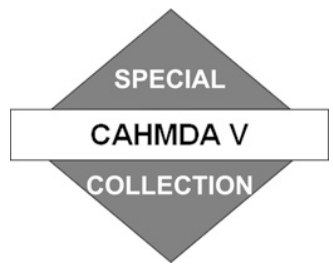

\title{
Calibration and Validation of a Distributed Energy-Water Balance Model Using Satellite Data of Land Surface Temperature and Ground Discharge Measurements
}

\author{
CHIARA CORBARI AND MARCO MANCINI \\ Department of Civil and Environmental Engineering, Politecnico di Milano, Milan, Italy
}

(Manuscript received 30 November 2012, in final form 25 July 2013)

\begin{abstract}
Distributed hydrological models of energy and mass balance need as inputs many soil and vegetation parameters, which are usually difficult to define. This paper will try to approach this problem by performing a pixel to pixel calibration procedure of soil hydraulic and vegetation parameters based on satellite land surface temperature data as a complementary method to the traditional calibration with ground discharge measurements at river control cross sections. These analyses are performed for the upper Po River basin (Italy) closed at the river cross section of Ponte della Becca with a total catchment area of about $38000 \mathrm{~km}^{2}$, for a calibration period from 2000 to 2003, and a validation period from 2004 to 2010. Moderate Resolution Imaging Spectroradiometer (MODIS) land surface temperature data and a distributed hydrological model, Flash-Flood Event-Based Spatially Distributed Rainfall-Runoff Transformation Energy Water Balance model (FEST-EWB), that solves the system of energy and mass balance equations as a function of the representative equilibrium temperature will be used. This equilibrium surface temperature is comparable to the land surface temperature as retrieved from operational remote sensing data. Results suggest that a combined calibration based on satellite land surface temperature and ground discharge is needed to correctly reproduce volume discharge and also spatially distributed maps of representative equilibrium temperature and evapotranspiration. Improvements of about $10 \mathrm{~mm} / 8$ days are obtained on evapotranspiration from the model calibrated with $Q$ and land surface temperature (LST) respect to the calibration based only on discharge.
\end{abstract}

\section{Introduction}

Calibration and validation of continuous distributed energy water balance models is a challenging task in hydrology and at the same time a complex issue owing to the difficulties related to the definition of which variables are representative of the single process and how reliable they are (Beven and Binley 1992; Refsgaard 1997; Rabuffetti et al. 2008; Brath et al. 2004). In flood and water balance simulations, the exact representation of the surface boundary conditions is important, in the form of soil moisture and snow accumulation over the ground (Castillo et al. 2003; Famiglietti and Wood 1994; Noilhan and Planton 1989). However, soil moisture, which is the

Corresponding author address: Chiara Corbari, Department of Civil and Environmental Engineering, Politecnico di Milano, Piazza Leonardo da Vinci, 32, Milan 20132, Italy.

E-mail: chiara.corbari@polimi.it key variable in the hydrologic water balance, is most of the time confined to an internal numerical model variable.

Calibration and validation of distributed models at basin scale generally refer to external variables, which are integrated catchment model outputs, and usually depend on the comparison between simulated and observed discharges at available river cross sections, which are usually very few (Rosso 1994; Rabuffetti et al. 2008). However, distributed models allow an internal validation, owing to their intrinsic structure (Dooge 1986; Fawcett et al. 1995; Refsgaard and Knudsen 1996; Gupta et al. 1999), so that model internal processes and variables can be controlled in each pixel of the domain [e.g., soil moisture (SM), land surface temperature (LST), and evapotranspiration fluxes (ET)]. In this way there is the opportunity to increase control points of evapotranspiration so that its accuracy can be improved. Satellite data for their intrinsic nature of spatially distributed information can be used for the internal calibration/ validation of distributed hydrological models in each 
pixel of the domain. This can be achieved with hydrologic modeling based on energy and water balance algorithms in conjunction with remote sensing data, in particular of land surface temperature, which is a connected variable to soil moisture and latent heat flux.

A complete review of models that compute evapotranspiration from remote sensing data is available in Kalma et al. (2008) and Verstraeten et al. (2008); in particular, the review of Overgaard et al. (2006) is focused on hydrological applications.

In past years, thermal infrared images have been widely used as an input variable of models for evapotranspiration estimates, setting up a family of energy balance models that compute evapotranspiration as the residual term of the energy balance equation without considering the mass balance [e.g., Surface Energy Balance Algorithm for Land (SEBAL) (Bastiaanssen et al. 1998), Surface Energy Balance System (SEBS) (Su 2002), Two Source Energy Balance (TSEB) (Norman et al. 1995), Simplified Surface Energy Balance Index (S-SEBI) (Roerink et al. 2000), and Atmosphere-Land Exchange Inverse Model (ALEXI) (Anderson et al. 1997)]. However, these models cannot directly provide soil moisture estimates (Hain et al. 2009); ET values are retrieved at satellite overpasses, and upscaling procedures are needed to scale estimates daily, even though these models have been widely validated (among others, Cammalleri et al. 2012; Galleguillos et al. 2011; Minacapilli et al. 2009; Jia et al. 2003; Timmermans et al. 2011).

Instead, continuous land surface models (LSMs) with mass and energy balances can address the limitations related to cloud coverage, typical of visible and thermal infrared satellite images. Moreover, they provide continuous estimates of evapotranspiration and also a direct and continuous estimate of soil moisture. Of course some limitations are present in these models, linked to the modeling of irrigation, lateral flows, and groundwater, which are difficult to parameterize. Another limitation is linked to the need of many hydraulic soil input parameters that are often not easily available at large scales even though they have an important role in the computation of the principal mass and energy fluxes. In the literature these parameters are usually defined using soil texture maps (Rawls and Brakensiek 1985), but problems of representativeness arise owing to pixel heterogeneity.

Satellite images of land surface temperature can help in the calibration of these parameters in each pixel of the analyzed domain, overcoming the traditional calibration based on a single multiplicative value retrieved from the comparison between observed and simulated ground discharge.

Even though little effort has been made in this direction, some examples are available. Franks and Beven
(1999) calibrated the TOPUP model (Franks et al. 1997) using satellite land surface temperatures for surface fluxes estimates; Crow et al. (2003) calibrated the Variable Infiltration Capacity (VIC) model using satellite LST and streamflow observations to improve evapotranspiration estimates; Gutmann and Small (2010) developed a method for the determination of the hydraulic properties of soil using satellite surface temperature in the Noah land surface model; and Corbari et al. $(2010 ; 2013)$ used land surface temperature remote sensing for the FlashFlood Event-Based Spatially Distributed Rainfall-Runoff Transformation Energy Water Balance (FEST-EWB) model validation in a highly heterogeneous area. Moreover, Gupta et al. (1999) show that a single criterion calibration, as for example based on ET, is not able to accurately reproduce land surface temperature, so a multicriteria calibration on a state variable and on an energy flux is needed to obtain reliable fluxes estimates.

In these continuous LSMs, satellite land surface temperature information is more often used in data assimilation schemes to update the state variables (e.g., soil moisture) or model parameters to reach the best estimate of the current state of a system (Crow and Wood 2003; Crow et al. 2008; Pan et al. 2008; Caparrini et al. 2004).

In this context, this paper has as the main objective to improve the accuracy of hydrological processes using satellite-based land surface temperature to calibrate soil and vegetation parameters as a complementary method to the traditional calibration with ground discharge measurements at river control cross sections. So a combined calibration of discharge and LST can outperform the calibration based only on discharge when the spatial distribution of evapotranspiration fluxes is considered.

A distributed hydrological, FEST-EWB (Mancini 1990; Corbari et al. 2011), which is based on the energy and water balance system as function of land surface temperature, will be used for these analyses. The model algorithm solves the system of energy and mass balance equations as a function of the equilibrium pixel temperature or representative equilibrium temperature (RET) that governs the energy and mass fluxes over a basin domain. LST is a critical model state variable and remote sensing LST can be effectively used, in combination with energy and mass balance modeling, to monitor latent and sensible heat fluxes as well as soil moisture conditions. This equilibrium surface temperature, which is an internal model variable, is compared to remote sensing land surface temperature to calibrate soil hydraulic and vegetation parameters in each single pixel of the study area.

The analysis are performed in the upper Po River basin (Italy) for the calibration period, from 2000 to 2003, and for 


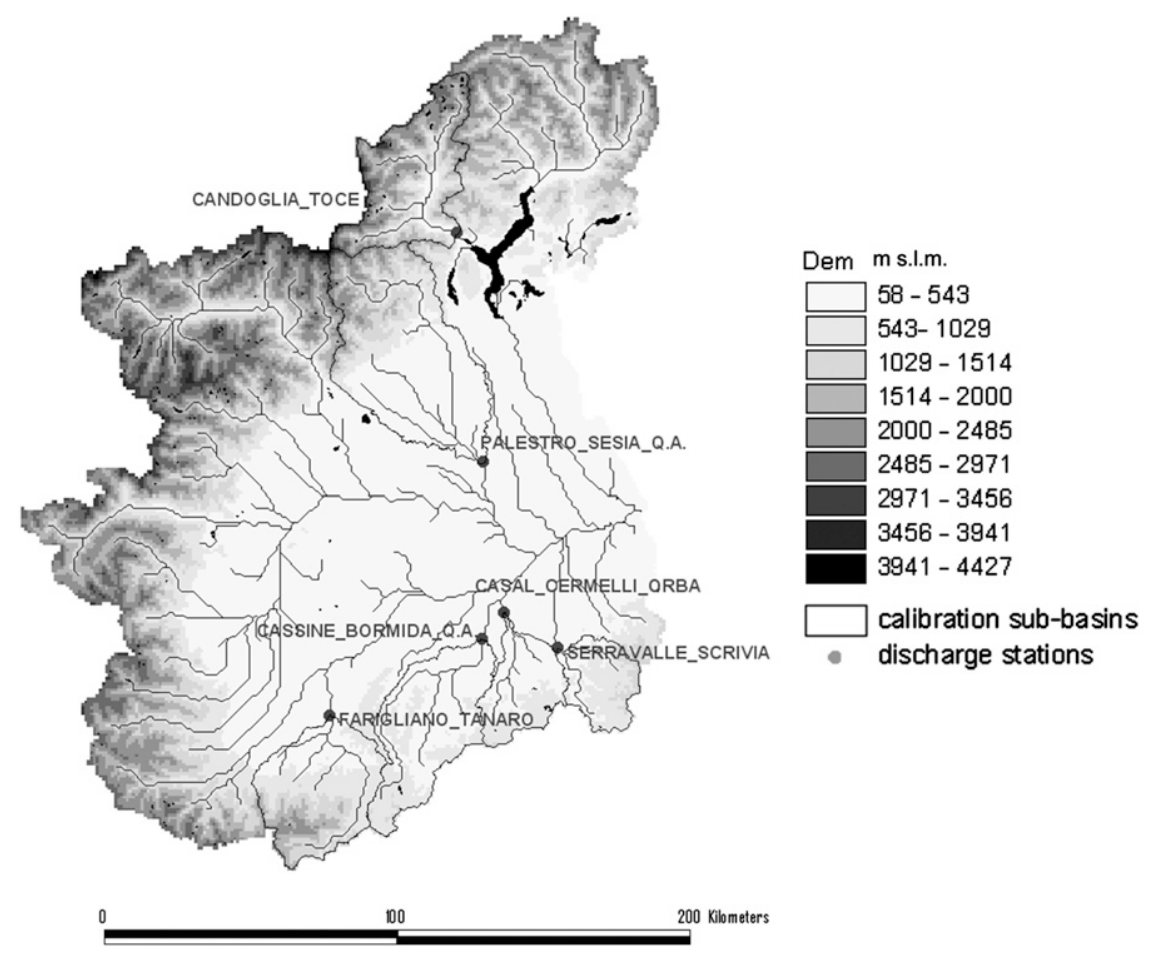

FIG. 1. Study area and available control cross sections.

the validation period, from 2004 to 2010, using Moderate Resolution Imaging Spectroradiometer (MODIS) LST data and ground discharge measurements.

\section{Study site and data}

The study site is the upper Po River basin (Italy), closed at the river cross section at Ponte della Becca, with a total catchment area of about $38000 \mathrm{~km}^{2}$. It is located in the Padana plain and bounded on three sides by mountain chains covering $73 \%$ of its territory (Fig. 1).

\section{a. Soil database and hydraulic properties}

A digital elevation model is available in raster format at $100 \mathrm{~m} \times 100 \mathrm{~m}$ spatial resolution from the Piemonte Environmental Protection Agency (ARPA). Land cover maps are available for the Italian part from the
Coordination of Information on the Environment Land Cover (CORINE) map updated in the year 2000 and for the Switzerland part from the CORINE map updated in the year 1990. Soil pedologic characteristics are also available from ARPA database. From this available basic thematic layer, hydraulic soil parameters required for the application of the hydrological model have been derived using the well-known database of Rawls and Brakensiek (1985). These include saturated hydraulic conductivity, residual and saturated soil moisture, pore size distribution index, wilting point, field capacity, and Brooks-Corey index. In Table 1 mean and standard deviation values of these parameters, from the literature, are reported.

\section{b. Hydrologic and meteorological data}

Available meteorological and hydrologic ground data are collected by the monitoring systems of the Regione

TABLE 1. Soil hydraulic and vegetation parameter means and standard deviations over the whole upper Po River basin from the literature values and after the calibration process with LST.

\begin{tabular}{|c|c|c|c|c|c|}
\hline \multicolumn{3}{|c|}{ From the literature } & \multicolumn{3}{|c|}{ After calibration } \\
\hline & Mean & Std dev & & Mean & Std dev \\
\hline$k_{\text {sat }}\left(\mathrm{m} \mathrm{s}^{-1}\right)$ & $2.28 \times 10^{-5}$ & $3.03 \times 10^{-5}$ & $k_{\text {sat }}$ modified & $6.12 \times 10^{-5}$ & $2.68 \times 10^{-4}$ \\
\hline depth (m) & 0.60 & 0.36 & depth modified & 1.04 & 0.80 \\
\hline$B C$ & 0.39 & 0.23 & BC modified & 0.22 & 0.15 \\
\hline $\mathrm{rs}_{\min }\left(\mathrm{s} \mathrm{m}^{-1}\right)$ & 180.13 & 166.09 & $\mathrm{rs}_{\min }$ modified & 111.10 & 115.71 \\
\hline
\end{tabular}


TABLE 2. Main characteristics of the catchments involved in the analysis.

\begin{tabular}{llc}
\hline \hline Cross section & River & Drained area $\left(\mathrm{km}^{2}\right)$ \\
\hline Casalcermelli & Orba & 798 \\
Cassine & Bormida & 1521 \\
Serravalle & Scrivia & 619 \\
Palestro & Sesia & 2587 \\
Farigliano & Tanaro & 1508 \\
Candoglia & Toce & 1531 \\
\hline
\end{tabular}

Piemonte, Regione Lombardia, and Switzerland. Data of rainfall, air temperature, incident shortwave solar radiation, air relative humidity, and horizontal wind velocity are available from 1 January 2000 to 31 December 2010 at an hourly or subhourly time step. The calibration period is then from 2000 to 2003 , while the validation period is from 2004 to 2010.

Hydrometric observations at $30-\mathrm{min}$ time steps are available at seven locations from 1 January 2000 to 31 December 2010. In the present analysis, some mediumsized subbasins with areas ranging from 422 to $3976 \mathrm{~km}^{2}$ are considered (Table 2).

\section{c. Land surface temperature from satellite images}

LST products from the MODIS radiometer on board satellite Terra [the MODIS/Terra LST/E Daily L3 Global 1-km Grid product (MOD11A1)], with a spatial resolution of $1 \mathrm{~km}$, are used (http://ladsweb.nascom. nasa.gov/index.html). 129 diurnal and nocturnal LST MODIS products are compared with the FEST-EWB land surface temperature over the 4 years of calibration. During the validation phase, 130 additional LST MODIS images have been considered. In particular, only images with cloud cover less than $20 \%$ over the entire area are selected.

\section{d. Vegetation information}

Leaf area index (LAI) and vegetation height are important parameters for modeling energy fluxes above vegetation, and the model is very sensitive to their variability. Height-vegetation curves are created for each type of vegetation defined from the CORINE land cover map. LAI maps, defined as one-side green leaf area per unit ground area, were retrieved from the MODIS LAI products (MOD 15-leaf area index) generated over an 8-day compositing period with a spatial resolution of $1 \mathrm{~km}$ were selected (Myneni et al. 2002). In the whole basin great variability is shown both in mountain areas and in the agricultural plain.

\section{e. Evapotranspiration from satellite images}

ET products from the MODIS radiometer (MOD16A2.105_MERRAGMAO product) are used in this study for model outputs comparison as an independent dataset. Of course, this dataset is not considered as "true measures" since it derives from a model with estimate errors. These data are available at spatial resolution of $1 \mathrm{~km}$ and at temporal resolution of 8 days. The product is the sum over these 8 days. The MOD16 ET data are estimated following $\mathrm{Mu}$ et al. (2011) based on the Penman-Monteith equation. Mu et al. report an average RMSE of $29.5 \mathrm{~W} \mathrm{~m}^{-2}$ of the 8-day latent heat flux product computed against 19 eddy covariance towers in the United States but with high discrepancies between climates and vegetation coverage. Ten ET MODIS products are selected between 13 June and 1 September 2002 for the comparison with simulated data.

\section{Methodology}

Soil and vegetation parameters in FEST-EWB will be calibrated from a simultaneous comparison between observed and simulated land surface temperature and discharges in order to improve not only hydrograph simulation but also the spatial variability of soil moisture and evapotranspiration.

\section{a. Hydrological model: FEST-EWB}

FEST-EWB is a distributed hydrological energywater balance model that computes all of the main processes of the hydrological cycle in each cell of the domain. A detailed description of the different updates of FEST-EWB hydrological model can be found starting from Mancini (1990) to Rabuffetti et al. (2008), Corbari et al. (2009, 2010), Ravazzani et al. (2011), and Corbari et al. (2011).

The model requires as input parameters 1) meteorological variables, such as air temperature, incoming shortwave radiation, wind velocity, precipitation, and air humidity; 2) soil parameters in distributed maps, such as the saturated hydraulic conductivity $\left(k_{\text {sat }}\right)$, the field capacity (fc), wilting point (wp), residual $\left(\theta_{r}\right)$ and saturated $\left(\theta_{s}\right)$ soil water content, Brooks-Corey index $(\mathrm{BC})$, bubbling pressure (bp), and soil depth (depth); 3) vegetation parameters, such as leaf area index (LAI), vegetation height $\left(h_{v}\right)$, and minimum stomatal resistance $\left(\mathrm{rs}_{\min }\right)$; and 4$)$ the digital elevation model (DEM) and land use/cover map.

Observed ground meteorological data are interpolated to a regular grid using the inverse distance weighting technique. Moreover, the air temperature spatial distribution takes into account the reduction of temperature with altitude, with a constant lapse rate of $-0.0065^{\circ} \mathrm{Cm}^{-1}$, while shortwave net radiation is distributed considering the effect of topography (Corbari et al. 2011). 
The model solves the system between energy and mass balance at the ground surface:

$$
\begin{aligned}
& \frac{d \mathrm{SM}}{d t}=\frac{P-R-\mathrm{PE}-\mathrm{ET}}{d z} \\
& R_{n}-G-H-\mathrm{LE}=\frac{d S}{d t},
\end{aligned}
$$

where SM (-) is the soil water content, $P(\mathrm{~mm})$ is the precipitation rate, $R(\mathrm{~mm})$ is the runoff flux, $\mathrm{PE}(\mathrm{mm})$ is the drainage flux, ET $(\mathrm{mm})$ is the evapotranspiration, $d z(\mathrm{~mm})$ is the soil depth, $R_{n}\left(\mathrm{~W} \mathrm{~m}^{-2}\right)$ is the net radiation, $G\left(\mathrm{~W} \mathrm{~m}^{-2}\right)$ is the soil heat flux, $H\left(\mathrm{~W} \mathrm{~m}^{-2}\right)$ is the sensible heat flux, LE $\left(\mathrm{W} \mathrm{m}^{-2}\right)$ is the latent heat flux, and $d S / d t$ encloses the energy storage terms, such as the photosynthesis flux and the crop and air enthalpy changes.

In particular ET is linked to the latent heat flux through the latent heat of vaporization $(\lambda)$ and the water density $\left(\rho_{w}\right)$ :

$$
\mathrm{LE}=\lambda \rho_{w} \mathrm{ET} .
$$

The latent heat flux, as reported in Corbari et al. 2011, is then computed as

$$
\mathrm{LE}=\frac{\rho_{a} c_{p}}{\gamma}\left(e^{*}-e_{a}\right)\left[\frac{f_{v}}{\left(r_{a}+r_{c}\right)}+\frac{1-f_{v}}{\left(r_{\mathrm{abs}}+r_{s}\right)}\right],
$$

where $\rho_{a}$ is the air density, $\gamma$ is the psychometric constant $\left(\mathrm{Pa}^{\circ} \mathrm{C}^{-1}\right), f_{v}$ is the vegetation fraction, and $c_{p}$ is the specific heat of humid air $\left(\mathrm{MJ} \mathrm{kg}^{-1} \mathrm{~K}^{-1}\right)$. The saturation vapor pressure $\left(e^{*}\right)$ is computed as function of RET, while the vapor pressure $\left(e_{a}\right)$ as a function of air temperature. The canopy resistance $\left(r_{c}\right)$ is expressed following Jarvis (1976), while the soil resistance $\left(r_{s}\right)$ is according to Sun (1982). The aerodynamic resistance $\left(r_{a}\right.$ for vegetation and $r_{\mathrm{abs}}$ for bare soil) is computed using the model from Thom (1975).

The sensible heat flux is computed as

$$
H=\rho_{a} c_{p}\left(\operatorname{RET}-T_{a}\right)\left[\frac{\left(1-f_{v}\right)}{r_{\mathrm{abs}}}+\frac{f_{v}}{r_{a}}\right],
$$

where $T_{a}$ is the air temperature $\left({ }^{\circ} \mathrm{C}\right)$.

The net radiation is computed as the algebraic sum of the incoming and outgoing shortwave and longwave radiation:

$$
R_{n}=R_{s}(1-r)+\xi_{c} \sigma\left(T_{a}^{4}\right)-\xi_{s} \sigma\left(\mathrm{RET}^{4}\right),
$$

where $R_{s}$ is the incoming shortwave radiation $\left(\mathrm{W} \mathrm{m}^{-2}\right), r$ is albedo, $\xi_{c}$ is the atmosphere emissivity, $\xi_{s}$ is soil emissivity, and $\sigma$ is the Stefan-Boltzmann constant $\left(\mathrm{W} \mathrm{m}^{-2} \mathrm{~K}^{-4}\right)$.
The soil heat flux is the heat changed for conduction with the subsurface soil and is evaluated as

$$
G=\left(C_{\text {soil }} / d z\right)\left(\operatorname{RET}-T_{\text {soil }}\right) .
$$

In Eq (7) $C_{\text {soil }}$ is soil thermal conductivity $\left(\mathrm{W} \mathrm{m}^{-1} \mathrm{~K}^{-1}\right)$ and $T_{\text {soil }}$ is soil temperature $\left({ }^{\circ} \mathrm{C}\right)$ at $10-\mathrm{cm}$ depth.

The energy budget equation is then solved explicitly looking for the RET that closes the balance becoming the representative equilibrium temperature of each pixel. In fact, it includes the heterogeneity of pixel surface, the multisource emissivity of land surface temperature, and the link with the aerodynamic resistance in the turbulent fluxes estimate. So, following the proposed approach, LST can be seen as a proxy of soil moisture and, thus, is a key variable in the fluxes estimates (Anderson et al. 2012).

The runoff routing throughout the hillslope and the river network is performed via a diffusion wave scheme based on the Muskingum-Cunge method in its nonlinear form with the time variable celerity. Details are given by Montaldo et al. (2007). Runoff is computed according to a modified Soil Conservation Service-Curve Number (SCS-CN) method extended for the continuous simulation (Ravazzani et al. 2007) where the potential maximum retention is updated cell by cell at the beginning of rainfall as a linear function of the degree of saturation.

The subsurface flow routing is computed with a linear reservoir routing scheme governed by the $k_{\text {prof }}$ parameter, which is a function of the ratio between cell dimension and inclination multiplied by the hydraulic conductivity for the deep soil. The hypodermic flow is computed only in slope cells where there is a relevant influence of the inclination of the mountainside, while in the plain this subsurface flow is not computed.

The calibration of snow accumulation and melt parameters is described in Corbari et al. (2009). The FESTEWB model is run at a spatial resolution of $1 \mathrm{~km}$ and with a time step of $1 \mathrm{~h}$.

\section{b. Calibration methodology}

The calibration procedure is based on a combined minimization of errors in terms of discharge and LST modifying the soil and vegetation parameters (combined LST and $Q$ calibration). These latter are modified on a pixel by pixel scale through the comparison between the model internal state variable RET and the remotely observed LST in order to constrain the surface processes. Volume discharge comparison is performed for the base flow parameter estimate $\left(k_{\text {prof }}\right)$. In fact, the land surface temperature is a driving factor of the superficial processes, especially during dry conditions, while discharges are a function of both the superficial 
and subsuperficial processes that the LST cannot control alone. Moreover, the traditional calibration based only on ground discharge data for few river sections lumps all hydrological processes together so that the correct spatial determination of mass and energy fluxes is more difficult. Instead, when a pixel to pixel calibration is performed, evapotranspiration can be better defined at pixel scale.

Soil and vegetation parameters subjected to calibration and their sensitivity to mass and energy flux changes are at first evaluated from a local scale analysis where an eddy covariance station is located. The parameters are then modified, in the physical ranges defined by Rawls and Brakensiek (1985), pixel by pixel (Table 1).

Several simulations are performed for a large number of parameters combinations following the "trial and error" approach. RET is compared pixel by pixel against each available remote LST image and statistical indices are computed. Soil and/or vegetation parameters are modified in each pixel of the domain by a different percentage according to matrix differences between LST and RET. Of course, a higher percentage of parameter change corresponds to a higher difference between observed and simulated land surface temperature. Different percentages of change (from $-50 \%$ to $+50 \%$ with an interval of $5 \%$ ) for each class of LST differences are tested covering a wide range of variation. From the sensitivity analysis performed at local scale, negative or positive changes are identified for each parameter positive or negative variation.

Ground observed flow data are used to asses propagation parameters by comparison with simulated discharge. Only cumulated volumes are considered because in this analysis only water quantity is needed and not the right timing of the flow hydrograph.

This procedure is in contrast to the traditional calibration based on the comparison with observed discharge data ( $Q$ calibration) where each soil parameter is multiplied or divided by a factor that is constant for the entire subbasin. Instead, in the LST calibration procedure each single pixel is multiplied by a different factor according to the relative difference in terms of temperature.

So, three different types of calibration procedures can be identified based on the comparisons: with ground discharge data ( $Q$ calibration), against satellite land surface temperature (LST calibration), and against both ground and satellite data (combined LST and $Q$ calibration).

Different statistical indexes are computed to evaluate the goodness of model estimates in terms of RET images and discharges. So the mean bias error (MBE), the absolute mean bias error (AMBE), the rms error (RMSE), the relative error (RE) and the absolute error (AE) are computed as follows:

$$
\begin{aligned}
\mathrm{RE} & =100 \frac{\sum_{i=1}^{n}\left(X_{\mathrm{sim}}^{i}-X_{\mathrm{obs}}^{i}\right) / X_{\mathrm{obs}}^{i}}{n}, \\
\mathrm{AE} & =100 \frac{\sum_{i=1}^{n}\left|\left(X_{\mathrm{sim}}^{i}-X_{\mathrm{obs}}^{i}\right) / X_{\mathrm{obs}}^{i}\right|}{n}, \\
\mathrm{MBE} & =\sum_{i=1}^{n}\left(X_{\mathrm{sim}}^{i}-X_{\mathrm{obs}}^{i}\right) / n \\
\mathrm{AMBE} & =\sum_{i=1}^{n}\left|X_{\mathrm{sim}}^{i}-X_{\mathrm{obs}}^{i}\right| / n, \\
\mathrm{RMSE} & =\left[\sum_{i=1}^{n}\left(X_{\mathrm{sim}}^{i}-X_{\mathrm{obs}}^{i}\right)^{2} / n\right]^{0.5},
\end{aligned}
$$

where $X_{\text {sim }}^{i}$ is the $i$ th simulated variable by FEST-EWB, $X_{\mathrm{obs}}^{i}$ is the $i$ th measured variable, $n$ the sample size, and $X_{\text {obs }}$ the average observed variable. The simulated and observed variables are always relative to the same variable, so that if RE, for example, is computed for LST, $X_{\text {sim }}, X_{\text {obs }}$, and $X_{\text {obs }}$ are all land surface temperature values.

Moreover, the Nash and Sutcliffe index, $\eta$, is also computed according to Nash and Sutcliffe (1970):

$$
\eta=1-\frac{\sum_{i=1}^{n}\left(X_{\mathrm{sim}}^{i}-X_{\mathrm{obs}}^{i}\right)^{2}}{\sum_{i=1}^{n}\left(X_{\mathrm{obs}}^{i}-\overline{X_{\mathrm{obs}}}\right)^{2}} .
$$

\section{c. Sensitivity analysis at soil and vegetation parameters changes}

To understand the effect of soil and vegetation parameter changes in FEST-EWB on land surface temperature and its connected variables (e.g., latent heat flux and soil moisture), a sensitivity analysis has been performed at local scale. This sensitivity analysis is performed in a maize field in northern Italy where an eddy covariance station is located $\left(45.11^{\circ} \mathrm{N}, 9.34^{\circ} \mathrm{E}\right)$ and meteorological data, energy fluxes, soil moisture, and land surface temperature measurements are available for the year 2010 during the agricultural season. The station is equipped with sensors to measure air temperature and the three components of wind speed, net radiation, latent heat flux, sensible heat flux, ground heat flux, air humidity, and soil water content every $30 \mathrm{~min}$ (Masseroni et al. 2012). Albedo is computed 


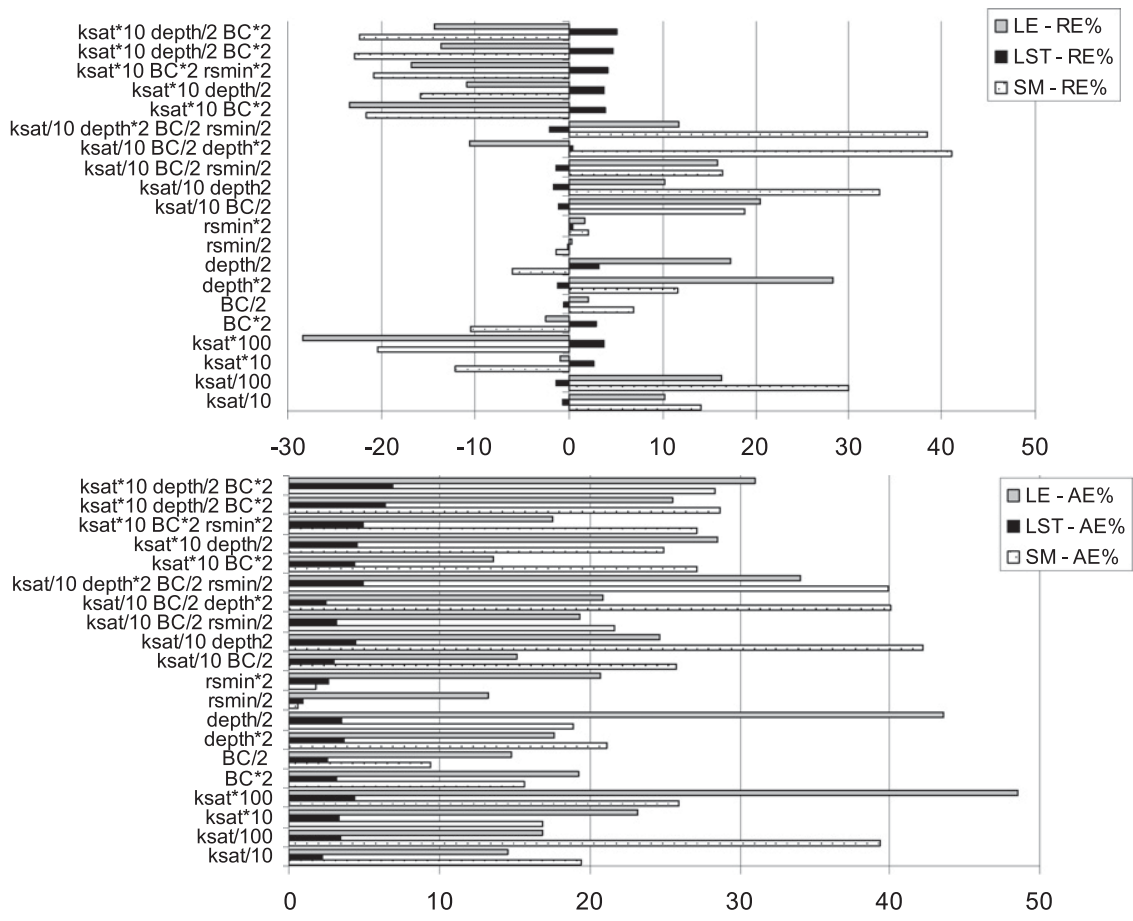

FIG. 2. Relative and absolute errors of land surface temperature, soil moisture, and latent heat flux for different simulation configurations at local scale.

from the observed outgoing shortwave radiation. Soil hydraulic parameters have been assigned from the database of Rawls and Brakensiek (1985) for the soil type of a sandy clay loam, which has been defined from ground measurements. The minimum stomatal resistance for maize has been fixed to a constant value of $100 \mathrm{~s} \mathrm{~m}^{-1}$. Soil depth has been fixed to $70 \mathrm{~cm}$, which corresponds to the maximum length reached by maize roots in the field during the analyzed year. The other required inputs are the vegetation height, LAI, and vegetation fraction, which have been measured in the field during the whole season.

Simulations have been performed, according to Fig. 2, considering changes of only one parameter a time or a combination of them. The parameters that produce higher changes of fluxes and that are then selected to be modified are soil hydraulic conductivity, Brooks-Corey index, soil depth, and minimum stomatal resistance. Then RE and AE are computed on land surface temperature, latent heat flux, and soil moisture for each simulation with respect to the simulation performed using the original configuration. When these latter statistical indices are computed for land surface temperature, no infinite values of RE or AE are found, owing to the fact that the station is operative only during the agricultural season when high temperatures are registered (Masseroni et al. 2012).
Mass and energy fluxes are affected by parameter changes, while land surface temperature is the least affected (Fig. 2). In particular, a decrement of saturated hydraulic conductivity, in terms of relative errors, leads to a negative change on land surface temperature with higher modification when $k_{\text {sat }}$ is divided by 100 . The opposite variations are found when $k_{\text {sat }}$ is multiplied by a factor of 10 and 100, respectively. The effects on soil moisture and evapotranspiration are opposite. In fact, an increase of soil saturated hydraulic conductivity leads to a decrease of SM and LE in consequence and owing to an increase in RET. A similar result is obtained if the Brooks and Corey index, which affects percolation, is multiplied by 2 .

The parameters that affect the representative equilibrium temperature most are the saturated hydraulic conductivity and soil depth. Then, if more parameters are modified simultaneously, the variations on energy and mass fluxes estimates increase. In fact, the highest differences of land surface temperature are found when all the parameters are changed.

A more specific analysis is then performed on the representative equilibrium temperature, focusing on its behavior during daytime and nighttime periods and for periods characterized by different soil moisture conditions (Fig. 3). Day and night are characterized by a different thermodynamic behavior so that during the night, 


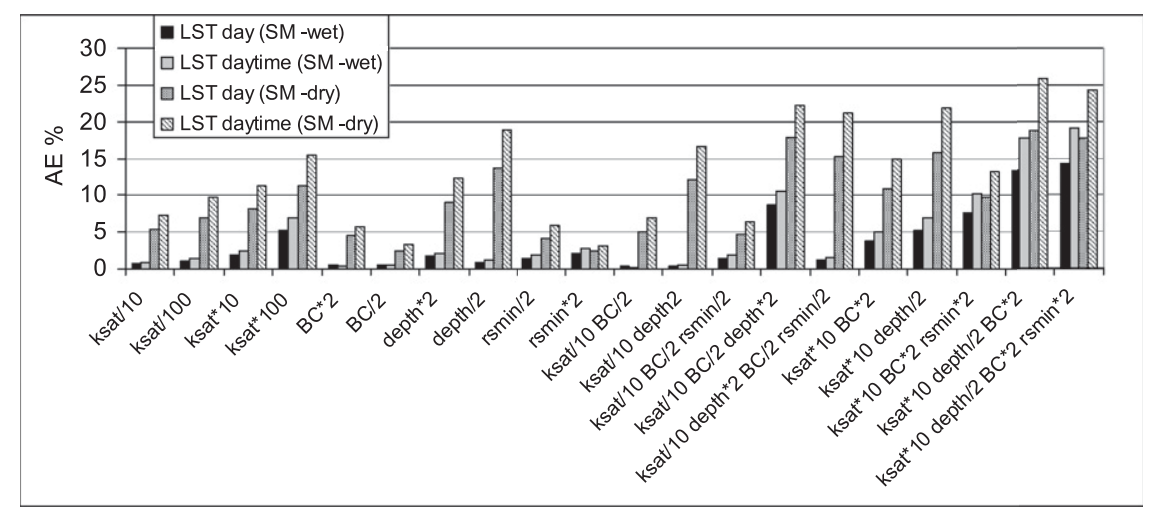

FIG. 3. Representative equilibrium temperature absolute errors differentiating between daytime and daily period and between wet and dry soil conditions for different simulation configurations at local scale.

because of the absence of shortwave radiation, smaller changes of LST are expected than during daytime. In fact, relative errors increase during the day and decrease during the night, with differences around $5 \%$.

Then, if relative and absolute errors are computed considering a period with low soil water content, around 0.16 , and a period of high water availability $(\mathrm{SM}=0.34)$, changes of soil hydraulic and vegetation parameters influence RET more during dry conditions than during wet conditions, with differences that can be higher than $18 \%$.

So some suggestions can be retrieved for the distributed model calibration: (i) RET, as well as soil moisture and latent heat flux, is influenced by changes of soil and vegetation parameters; (ii) RET during daytime periods, which are characterized by high incoming radiation, is affected more by parameter changes than during nighttime; and (iii) higher differences on RET are present during dry conditions.

\section{Results}

Land surface temperature, flow discharge, and evapotranspiration results are reported for the calibration period, from 2000 to 2003, and for the validation period, from 2004 to 2010.

\section{a. Calibration}

\section{1) Calibration against Remote Sensing LST}

The calibration of soil hydraulic and vegetation parameters for the upper Po River basin is performed through the comparison between RET estimates from the FEST-EWB run using different configurations and MODIS satellite data of LST that were chosen as a benchmark in this study.

According to section $3 \mathrm{~b}$, the FEST-EWB model is, at first, run in the original configuration (O-SoVeg) where soil hydraulic parameters were assigned according to
Rawls and Brakensiek (1985) for the different types of soil. Starting points are the results obtained from the sensitivity analysis performed at local scale so that the calibration of the vegetation and soil parameters for the distributed domain will be performed considering only daytime hours and dry conditions. In particular daytime images during June, July, and August are considered. These local scale analyses are also useful to define how a percentage increase or decrease of a parameter can lead to a positive or negative change in land surface temperature and, so, its connected variables as soil moisture and evapotranspiration. Each parameter, in each pixel, is then increased or decreased a percentage in each pixel considering the difference between simulated and observed land surface temperature.

In Fig. 4, for example, simulated and observed land surface temperature images along with the relative histograms are reported for 1300 UTC 6 July 2000. RET is shown in the O-SoVeg configuration and higher temperatures are found in respect to MODIS data. For this first simulation, MBE and AMBE denote a mean overestimation of $1.8^{\circ}$ and $3.4^{\circ} \mathrm{C}$, while RMSE is equal to $4.3^{\circ} \mathrm{C}$.

In Table 3 the evaluation parameters are computed for all 129 RET images from FEST-EWB in the original $\mathrm{O}-\mathrm{SoV}$ eg configuration. Each statistical parameter is computed for each single image and then an average over the 129 images is calculated. MBE and AMBE denote a mean overestimation of $2.4^{\circ}$ and $4.3^{\circ} \mathrm{C}$, and RMSE is equal to $5.4^{\circ} \mathrm{C}$. If daytime images and nighttime maps are considered separately, higher errors are found during the day with $\mathrm{AMBE}$ of $4.6^{\circ} \mathrm{C}$ and RMSE of $5.7^{\circ} \mathrm{C}$, while an $\mathrm{AMBE}$ of $2.8^{\circ} \mathrm{C}$ is reached at night with RMSE of $3.6^{\circ} \mathrm{C}$. Summarizing all of the performed analysis, FEST-EWB in the O-SoVeg configuration generally overestimates the land surface temperature from MODIS. 


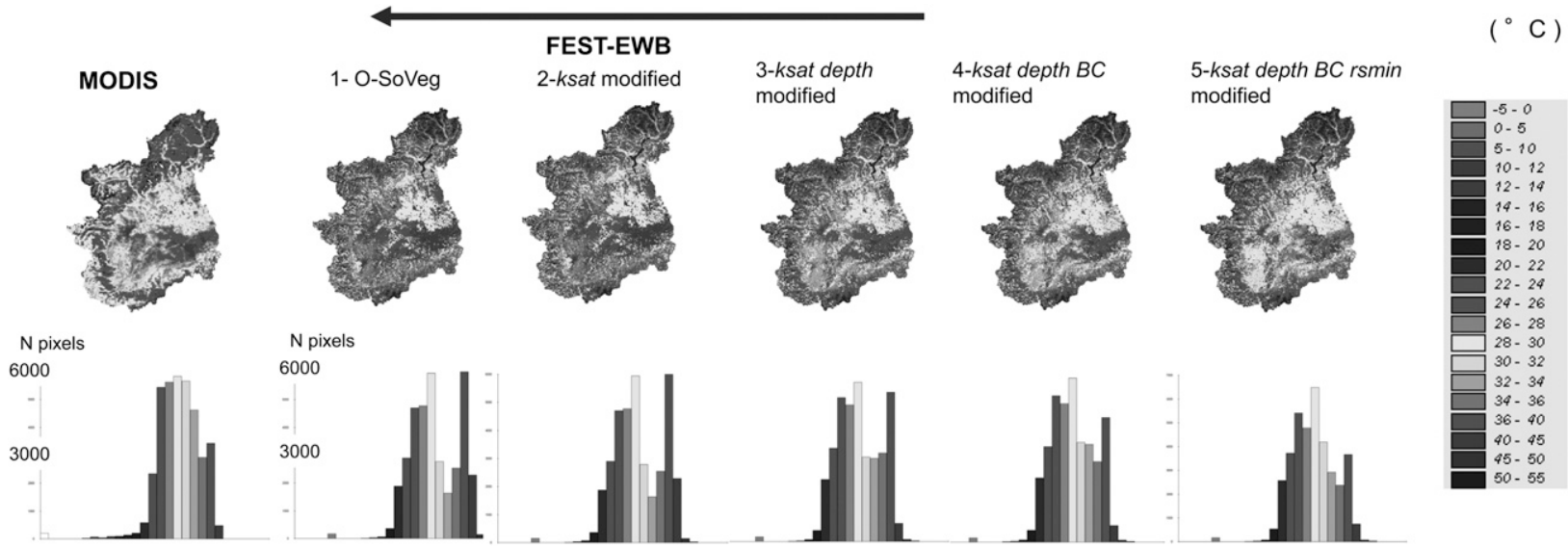

FIG. 4. Simulated and observed land surface temperature images along with the relative histograms are reported for 1300 UTC 6 Jul 2000.

The second simulation is based on pixel-to-pixel calibration of the saturated hydraulic conductivity according to the differences between observed and simulated LST. In Fig. 4, RET for 1300 UTC 6 July 2000 is also reported for this simulation, and a slight modification is visible with small changes in the histograms. The statistical parameters confirm these findings with MBE and AMBE that denote a mean overestimation respectively of $1.9^{\circ}$ and $3.9^{\circ} \mathrm{C}$.

Other simulations are then performed, and $k_{\text {sat }}$ has been changed multiplying its original value of the O-SoVeg configuration in each pixel by values between $10^{-2}$ and $10^{2}$, Brooks and Corey index between 0.1 and 0.8 , soil depth between 0.5 and 2 , and $\mathrm{rs}_{\min }$ between 0.5 and 2 . In Table 1 the means and the standard deviations of the modified soil hydraulic and vegetation parameters are reported, showing that the new values are included within literature ranges (Rawls and Brakensiek 1985).

In Fig. 4 RET images for 1300 UTC 6 July 2000 are reported for other simulations, showing how land surface temperature is affected by the changes in soil hydraulic and/or vegetation parameters. The third reported simulation is performed with a modified $k_{\text {sat }}$ and depth; the fourth with $k_{\text {sat }}$, depth, and BC; while the fifth, in addition to the fourth, has a modified map of $\mathrm{rs}_{\text {min }}$.
A decrease in land surface temperature is generally visible from the first to the fifth simulation. The RET frequency distribution, which denotes a more similar shape to that of LST from MODIS, is the one related to the fifth simulation, where $k_{\mathrm{sat}}$, depth, $\mathrm{BC}$, and $\mathrm{rs}_{\min }$ are modified. This is also confirmed by the lowest statistical parameters of this simulation with $\mathrm{AMBE}$ of $2.8^{\circ} \mathrm{C}$ and $\mathrm{MBE}$ of $1.1^{\circ} \mathrm{C}$.

When all 129 selected images are considered for the 4 years of simulation, the parameter combination that minimizes AMBE to $2.2^{\circ} \mathrm{C}, \mathrm{MBE}$ to $0.9^{\circ} \mathrm{C}$, and RMSE to $3.4^{\circ} \mathrm{C}$ is linked to a modification of $k_{\text {sat }}$, depth, $B C$, and $\mathrm{rs}_{\min }$. In Table 3 the statistical analyses are reported for all simulations, confirming the previous obtained results for the single image for 1300 UTC 6 July 2000. In Fig. 5, the absolute mean bias error, computed as the pixel by pixel LST difference and then averaged over the entire image, is reported for each image for the different simulations, confirming the global previous results.

Because of the high heterogeneity of the basin, a more detailed analysis is then performed so as to better understand the thermodynamic behaviors of the different types of the soil-vegetation system. According to the CORINE land cover map, the basin is subdivided into homogeneous areas identifying different land use: forest,

TABLE 3. The mean bias error (MBE), the absolute mean bias error (AMBE), the rms error (RMSE), and the Nash-Sutcliffe index ( $\eta$ ) are computed for all 129 RET images against MODIS LST for the performed simulations during the calibration phase.

\begin{tabular}{clcrr}
\hline \hline Simulation & \multicolumn{1}{c}{ Modified parameters } & MBE $\left({ }^{\circ} \mathrm{C}\right)$ & AMBE $\left({ }^{\circ} \mathrm{C}\right)$ & RMSE $\left({ }^{\circ} \mathrm{C}\right)$ \\
\hline 1 & O-SoVeg & -2.4 & 4.5 & 5.3 \\
2 & $k_{\text {sat }}$ modified & -1.8 & 3.9 & 4.8 \\
3 & depth modified & -1.7 & 3.8 & 0.45 \\
4 & BC modified & -2.1 & 4.2 & 0.51 \\
5 & $k_{\text {sat }}$, BC, and depth modified & -1.1 & 3.3 & 5.1 \\
6 & $k_{\text {sat }}$ and depth modified & -1.1 & 2.9 & 3.9 \\
7 & $k_{\text {sat }}$, BC, rs $_{\text {min }}$, and depth modified & 0.9 & 2.2 & 4.1 \\
\hline
\end{tabular}




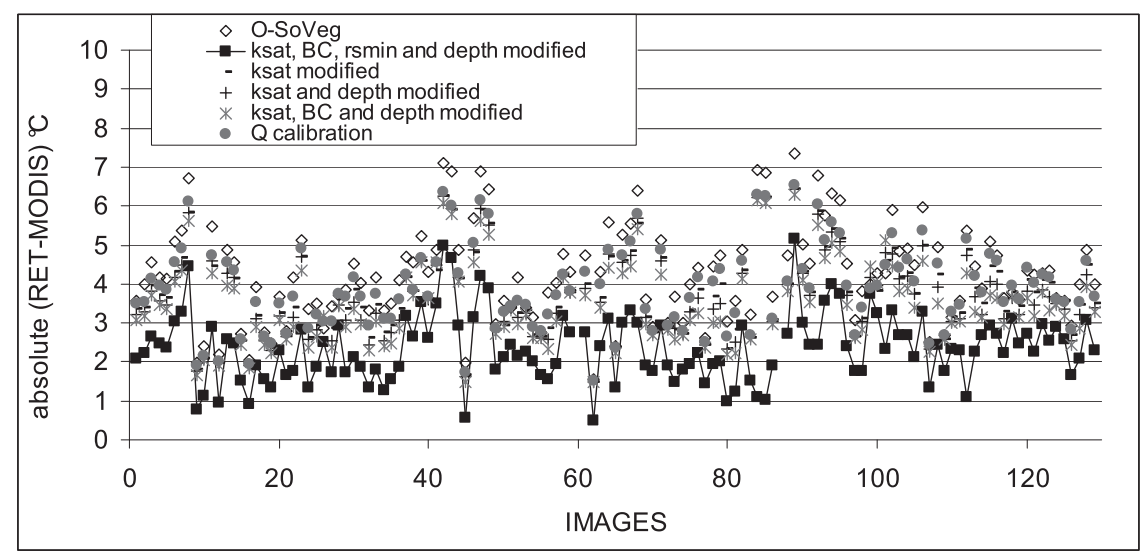

FIG. 5. AMBE between LST from MODIS and RET for different FEST-EWB simulations for each of 129 images selected for the calibration.

agricultural area, pasture, sparse vegetation, and rice paddies. Urban areas have been excluded from this comparison because the model does not simulate them. In Table 4 AMBE and RMSE between MODIS LST and RET from the O-SoVeg simulation and from the selected simulation with modified $k_{\mathrm{sat}}, \mathrm{BC}, \mathrm{rs}_{\min }$, and depth are reported. For the calibration phase the statistical indices are computed for all 129 images. A general improvement is obtained in each land use class if the calibrated simulation is considered. Higher errors with $\mathrm{AMBE}$ of $3.4^{\circ} \mathrm{C}$ still remain in the agricultural areas, probably due to the difficulties to exactly represent vegetation dynamic in these large areas, such as the exact period of sowing and harvesting or the exact type of crop, and to know the irrigation dates for each single field.

In Fig. 6 autocorrelation functions (AC) of LST from MODIS and RET have been computed for two selected dates, 1100 UTC 22 May 2000 and 1300 UTC 19 July 2002 , in order to understand the capability of FESTEWB model to correctly reproduce the spatial distribution of the surface heterogeneities of the upper Po River basin. A similar behavior of LST from MODIS and RET from FEST-EWB is shown with a similar degree of correlation decreasing with the distance.

Changes in soil hydraulic and vegetation parameters lead to modifications not only in the representative equilibrium temperature but also in its interconnected variables, such as soil moisture and evapotranspiration. So soil moisture and latent heat flux maps for the selected dates of 1100 UTC 22 May 2000 and 1300 UTC 19 July 2002 are then analyzed in terms of AC functions and compared with the autocorrelation functions of land surface temperature. A similar shape of the functions is found (Fig. 6).

TABLE 4. AMBE and RMSE of land surface temperature for different land uses for the O-SoVeg and the $k_{\mathrm{sat}}$, BC, $\mathrm{rs}_{\mathrm{min}}$, and depth modified simulations during the calibration (129 images) and validation (130 images) phases.

\begin{tabular}{|c|c|c|c|c|}
\hline \multirow[b]{2}{*}{ Land use } & \multicolumn{2}{|c|}{ Calibration } & \multicolumn{2}{|c|}{ Validation } \\
\hline & O-SoVeg & $\begin{array}{c}k_{\mathrm{sat}}, \mathrm{BC}, \mathrm{rs}_{\min } \text {, and } \\
\text { depth modified }\end{array}$ & O-SoVeg & $\begin{array}{c}k_{\text {sat }}, \mathrm{BC}, \mathrm{rs}_{\min }, \text { and } \\
\text { depth modified }\end{array}$ \\
\hline \multicolumn{5}{|c|}{$\operatorname{AMBE}\left({ }^{\circ} \mathrm{C}\right)$} \\
\hline Paddies & 5.70 & 3.3 & 5.7 & 3.1 \\
\hline Forests & 3.65 & 2.2 & 4.5 & 1.8 \\
\hline Lake & 3.20 & 3.2 & 2.7 & 2.7 \\
\hline Sparse vegetation & 5.62 & 2.1 & 5.99 & 2.6 \\
\hline Pasture & 5.75 & 1.5 & 6.19 & 1.9 \\
\hline Agricultural area & 5.28 & 3.4 & 5.71 & 3.7 \\
\hline \multicolumn{5}{|c|}{$\operatorname{RMSE}\left({ }^{\circ} \mathrm{C}\right)$} \\
\hline Paddies & 6.07 & 3.7 & 6.07 & 4.6 \\
\hline Forests & 4.78 & 4.3 & 5.44 & 3.8 \\
\hline Lake & 3.80 & 3.8 & 4.8 & 4.8 \\
\hline Sparse vegetation & 7.07 & 3.6 & 7.12 & 2.6 \\
\hline Pasture & 6.22 & 3.9 & 6.67 & 3.4 \\
\hline Agricultural area & 5.96 & 4.1 & 6.36 & 4.5 \\
\hline
\end{tabular}



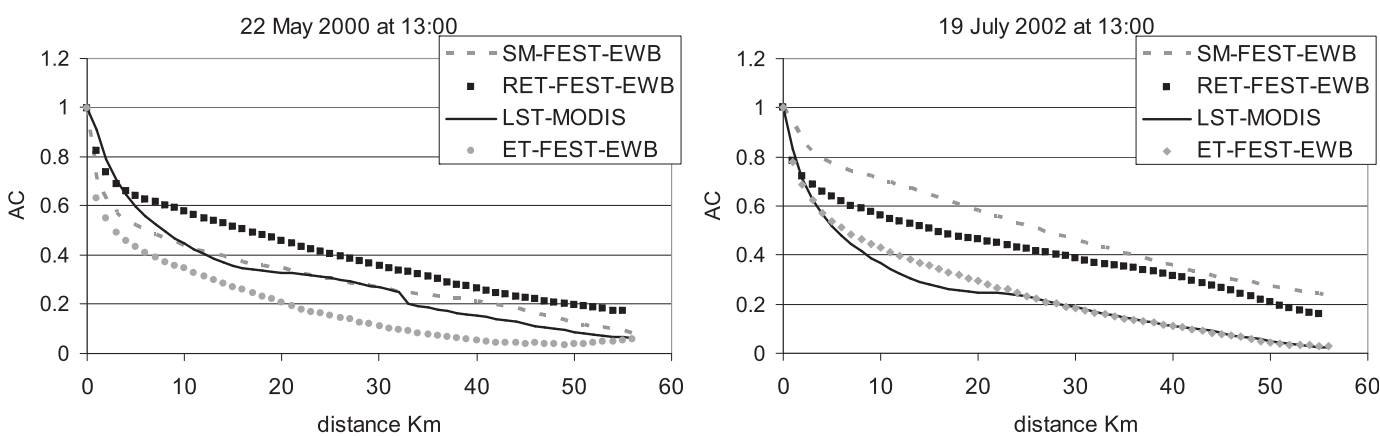

FIG. 6. Autocorrelation functions for RET, ET, and SM from the selected simulation and LST from MODIS for the two selected dates, 1100 UTC 22 May 2000 and 1300 UTC 19 Jul 2002.

\section{2) CAlibration AgAinst GRound Discharge MEASUREMENTS}

The FEST-EWB model has also been calibrated performing the traditional trial and error methodology based on the comparison between observed and simulated discharges in terms of cumulated volume in some river cross sections (Beven and Binley 1992; Brath et al. 2004; Rabuffetti et al. 2008). Different subbasins have been considered (Table 2).

Soil hydraulic conductivity, Brooks and Corey index, soil depth, and $k_{\text {prof }}$ are the parameters, which are now subjected to calibration. Each parameter is multiplied or divided by a factor that is constant for the entire subbasin. This procedure is opposite to the pixel-to-pixel calibration procedure where each single pixel is multiplied by a different factor. In Table 5 the multiplier factors of each parameter are reported for the subbasins considered. It is expected that an increase of deep soil conductivity implies an increase of hypodermic flow, as well as a decrease of $k_{\text {sat }}$, leads to an increase of the drainage process. The $\mathrm{CN}$ map, surface roughness coefficient, and section width were not modified in the calibration process.

The simulation period from 1 January 2000 to 31 July 2000 is considered as a startup period since the snow initial condition is zero.

In Fig. 7, relative errors between observed and simulated volumes for each control cross section from the FEST-EWB run in the different configurations are shown: O-SoVeg, calibration of soil hydraulic parameters against ground discharge data ( $Q$ calibration), and calibration of soil hydraulic and vegetation parameters against land surface temperature (LST calibration). It is clearly visible that, before calibration, FEST-EWB greatly overestimates or underestimates observed data in comparison to the observed ground volumes ( $\mathrm{RE}$ between $72 \%$ and $-42 \%$ ). If LST calibration errors are analyzed, high values are still found ranging between
$52 \%$ and $-31 \%$. This finding is strictly related to the impossibility to calibrate $k_{\text {prof }}$ using only satellite LST, as explained in paragraph $3 \mathrm{~b}$. If the results obtained after the calibration process against ground discharge data are analyzed, a generalized improvement of model performances in terms of flood volume is found with errors ranging from $-14 \%$ to $26 \%$.

So, following these results, a combined calibration against satellite LST and ground river discharge is needed (combined LST and $Q$ calibration). So a new simulation has been performed: $\mathrm{BC}, k_{\mathrm{sat}}$, depth, and $\mathrm{rs}_{\min }$ are modified pixel by pixel according to satellite LST data while $k_{\text {prof }}$ is according to ground discharge data. In Table 5 the multiplier factors for $k_{\text {prof }}$ for this simulation are reported. Relative errors between observed and simulated volume now show a general improvement between $-11 \%$ and $14 \%$ (Fig. 7 ).

\section{3) COMPARISON OF CALIBRATION METHODS}

The results obtained from the calibration based on ground discharge suggest that, for each subbasin, a reasonable agreement can be obtained on hydrograph volumes; on the other hand, RET and its corresponding SM values are not correctly spatially distributed. On the contrary, if the calibration is performed only against

TABLE 5. Multiplier factors of soil hydraulic parameters for each river subbasin for the $Q$ calibration procedure.

\begin{tabular}{|c|c|c|c|c|c|}
\hline & \multicolumn{4}{|c|}{$Q$ calibration } & \multirow{2}{*}{$\begin{array}{c}\text { Combined LST } \\
\text { and } Q \text { calibration } \\
k_{\text {prof }}\end{array}$} \\
\hline & $k_{\text {sat }}$ & depth & $\mathrm{BC}$ & $k_{\text {prof }}$ & \\
\hline Casal Cermelli & $/ 10$ & $\times 1$ & $\times 1$ & $\times 10^{3}$ & $\times 10^{2}$ \\
\hline Candoglia & $/ 10$ & $\times 1$ & 12 & $\times 10^{4}$ & $\times 10^{3}$ \\
\hline Cassine & $/ 100$ & $\times 2$ & 12 & $\times 10^{2}$ & $\times 10^{3}$ \\
\hline Farigliano & $/ 100$ & $\times 1$ & 12 & $\times 10^{4}$ & $\times 10^{4}$ \\
\hline Palestro & $/ 100$ & $\times 1$ & $\times 1$ & $\times 10^{4}$ & $\times 10^{4}$ \\
\hline Serravalle & $/ 100$ & $\times 1$ & 12 & $\times 10$ & $\times 10^{2}$ \\
\hline
\end{tabular}




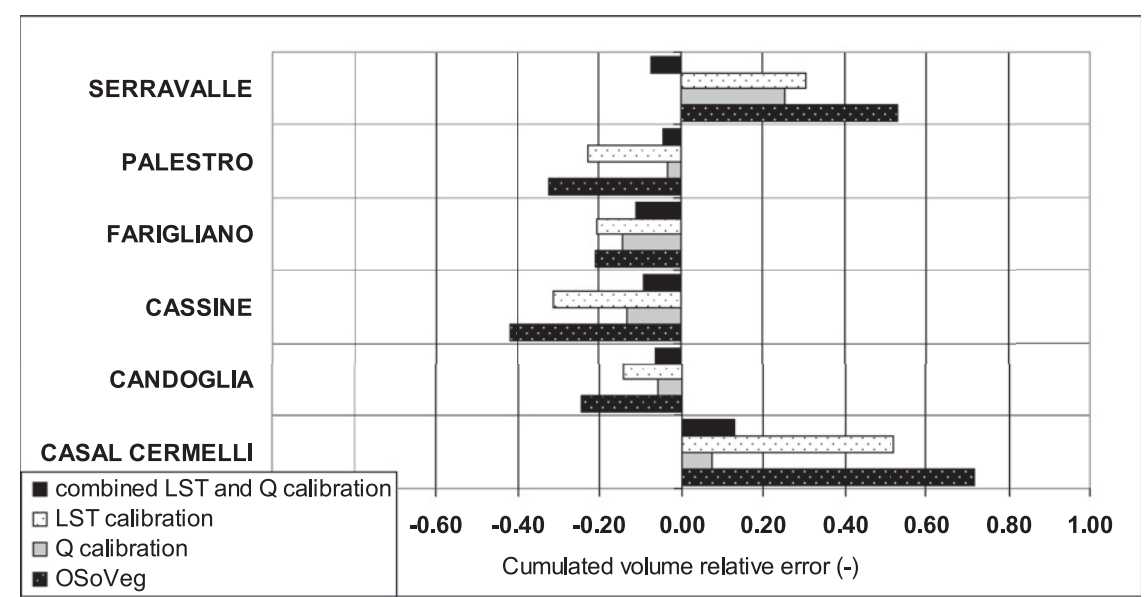

FIG. 7. Relative errors for the calibration period between observed and simulated volumes from FEST-EWB run in the O-SoVeg configuration and after the calibration processes.

satellite land surface temperature images, river flow volumes are not correctly reproduced.

In Fig. 8, the comparison between MODIS LST and two RET images, respectively from the simulation calibrated pixel by pixel with satellite LST and from the simulation calibrated against ground discharge data, is reported for 1300 UTC 6 July 2000 for the Bormida subbasin closed at Cassine (Table 2). A better agreement is found between LST from MODIS and RET calibrated against LST. These results are confirmed also by the average pixel by pixel difference between LST from MODIS and RET from the simulation calibrated with LST with a value of $0.8^{\circ} \mathrm{C}$ (standard deviation of $2.2^{\circ} \mathrm{C}$ ); when MODIS LST and RET from the simulation calibrated against discharge data are considered, the mean difference is $1.7^{\circ} \mathrm{C}$ and the standard deviation $3.5^{\circ} \mathrm{C}$. This finding is also confirmed by the comparison of AMBE, for each of the 129 images used for calibration, between LST from MODIS and RET from different FEST-EWB simulations, considering also the $Q$ calibration simulation (Fig. 5). In fact, with respect to the LST calibration (modifications of $k_{\text {sat }}$, depth, BC,
MODIS

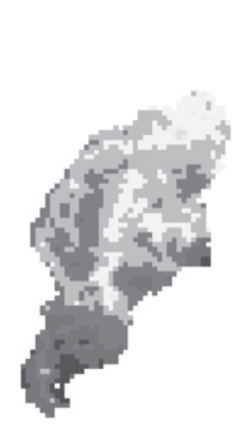

OSoVeg

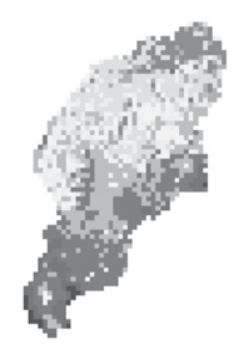

Pixel numbers

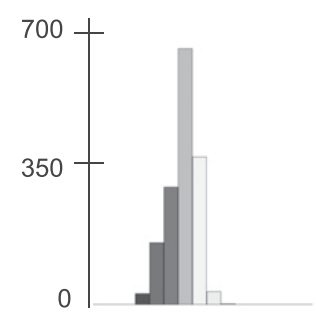

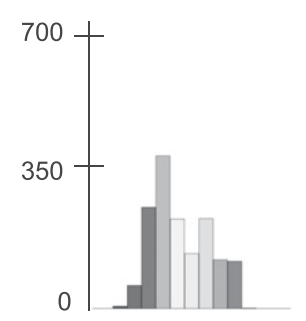

\section{FEST-EWB}

LST calibration
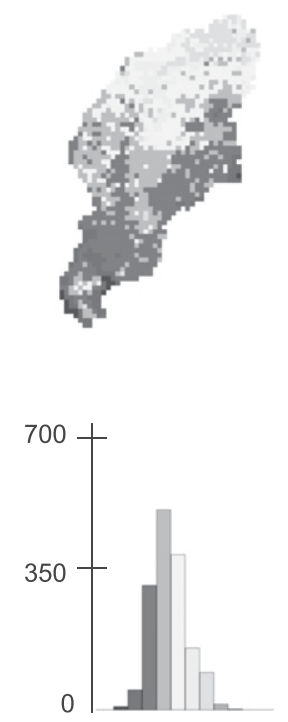

Q calibration
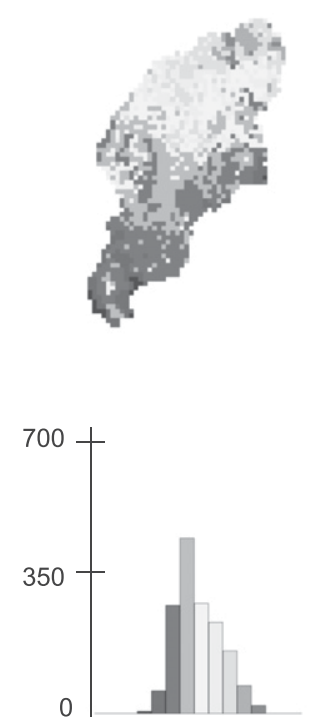

$\circ \mathrm{C}$

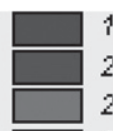

$18-20$

$20-22$

$22-24$

$24-26$

$26-28$

$28-30$

$30-32$

$32-34$

$34-36$

$36-40$

FIG. 8. LST from MODIS and from FEST-EWB for the not-calibrated simulation, LST calibration, and $Q$ calibration for 1300 UTC 6 Jul 2000 for the Bormida subbasin closed at Cassine. 
MODIS

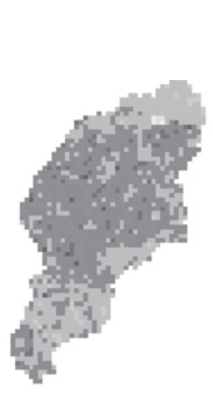

FEST-EWB

$$
\text { LST + Q }
$$

calibration

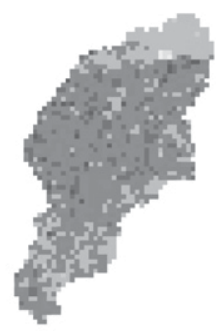

Pixel numbers
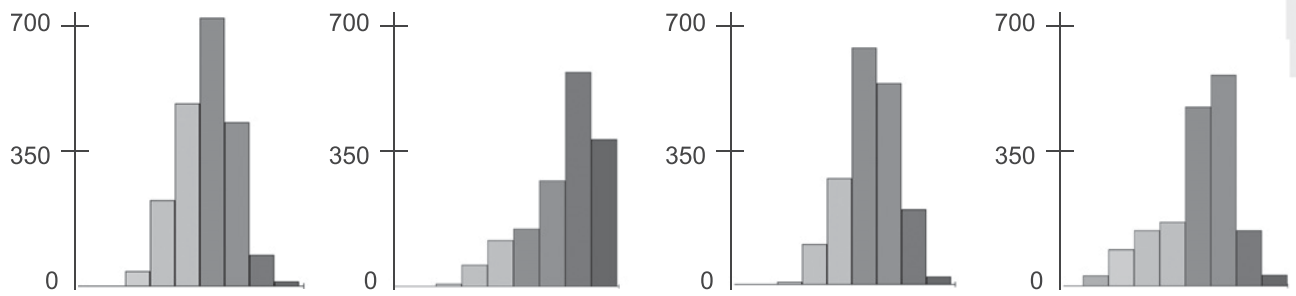

$\mathrm{mm} /$ day

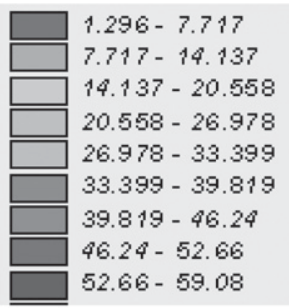

FIG. 9. ET from MODIS and from FEST-EWB for the not-calibrated simulation, LST $+Q$ calibration, and $Q$ calibration from 7 to $15 \mathrm{Jul}$ 2002 for the Bormida subbasin closed at Cassine.

and $\mathrm{rs}_{\min }$ ) where AMBE of $2.2^{\circ} \mathrm{C}, \mathrm{MBE}$ of $0.9^{\circ} \mathrm{C}$, RMSE of $3.4^{\circ} \mathrm{C}, \mathrm{RE}$ of $5.2 \%$ were found, $Q$ calibration results are $\mathrm{AMBE}$ of $3.9^{\circ} \mathrm{C}, \mathrm{MBE}$ of $-1.95^{\circ} \mathrm{C}$, RMSE of $4.4^{\circ} \mathrm{C}$, and $\mathrm{RE}$ of $9.2 \%$.

To strengthen the usefulness of a combined LST and $Q$ calibration, evapotranspiration outputs from FESTEWB are compared pixelwise with the independent dataset of ET maps from the MODIS algorithm. This comparison allows one to analyze both the area average ET value and the correct spatial distribution of modeled evapotranspiration. Comparison of 10 groups of 8-day evapotranspiration from MODIS and from the calibrated FEST-EWB with the three different calibration procedures is then performed between 13 June and 1 September 2002 to understand the improvement of the combined $Q$ and LST calibration. The $Q$ calibration leads to RMSE of $15.4 \mathrm{~mm}$, while LST calibration to $10 \mathrm{~mm}$. ET estimates are improved when the combined LST and $Q$ calibration is performed, leading to a decrease of RMSE to $5.1 \mathrm{~mm}$.

If the spatial distribution aspect is considered, Fig. 9 shows maps and the relative histograms of ET from
MODIS and of simulated evapotranspiration from the noncalibrated model, from $Q$ calibrated model, and from $\mathrm{LST}+Q$ calibrated model for the 8-day period from 7 July 2002. The average pixel by pixel difference between ET from MODIS and from the simulation calibrated with $\mathrm{LST}+Q$ is equal to $3.4 \mathrm{~mm} / 8$ days with a standard deviation of $3.2 \mathrm{~mm} / 8$ days; when MODIS ET and ET from the simulation calibrated against discharge data are considered, the mean difference is equal to $13.4 \mathrm{~mm} / 8$ days and the standard deviation to $6.5 \mathrm{~mm} / 8$ days.

\section{b. Validation}

\section{1) VALidAtion AgAinst REMOTE SENSING LST}

During the validation phase, 130 MODIS LST images are compared with RET data from the simulation with the original configuration and the selected simulation with $k_{\text {sat }}$, depth, $\mathrm{BC}$, and $\mathrm{rs}_{\min }$ modified. In Table 6 the statistical results of the comparison of land surface temperatures are reported for these two simulations and the errors are found to be in accordance with the results

TABLE 6. The mean bias error, the absolute mean bias error, the rms error, the relative error, and the Nash-Sutcliffe index are computed for all the 130 RET images against MODIS LST for the performed simulations during the validation phase.

\begin{tabular}{clccr}
\hline \hline Simulation & \multicolumn{1}{c}{$\begin{array}{c}\text { Modified } \\
\text { parameters }\end{array}$} & MBE $\left({ }^{\circ} \mathrm{C}\right)$ & AMBE $\left({ }^{\circ} \mathrm{C}\right)$ & RMSE $\left({ }^{\circ} \mathrm{C}\right)$ \\
\hline 1 & $\mathrm{O}-\mathrm{SoVeg}$ & -2.5 & 5.4 & 6.4 \\
2 & $k_{\text {sat }}, \mathrm{BC}, \mathrm{rs}_{\min }$, and depth modified & -1.3 & 2.4 & 0.4 \\
\hline
\end{tabular}




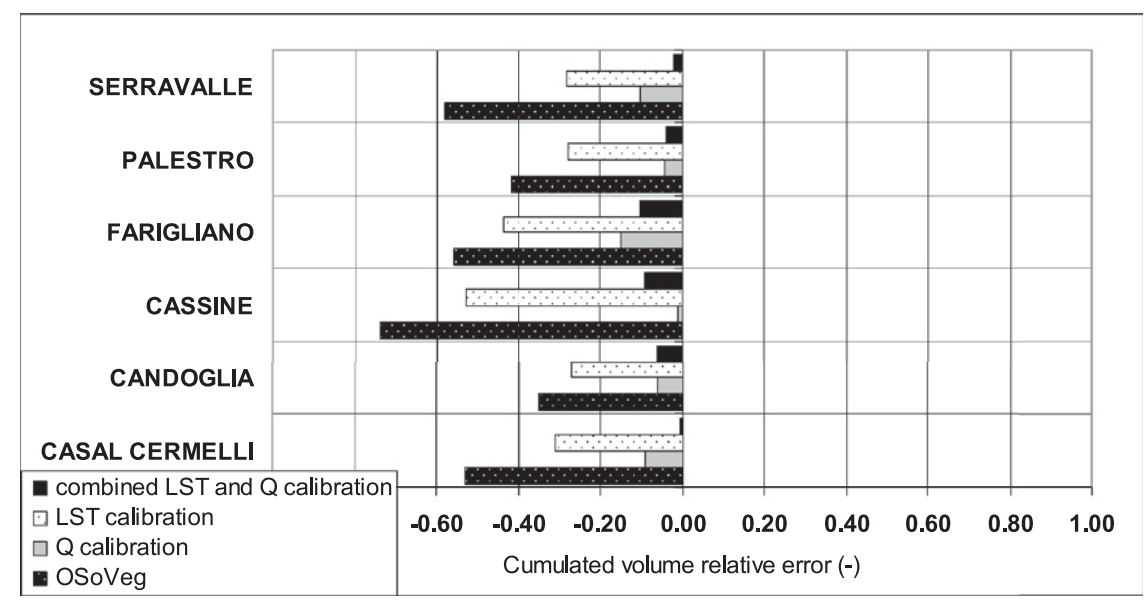

FIG. 10. Relative errors for the validation period between observed and simulated volumes from FEST-EWB run in the O-SoVeg configuration and after the calibration processes.

obtained during the calibration period with low AMBE for the calibrated simulation.

In Table 4 AMBE and RMSE for the different land use classes are also reported for the O-SoVeg and the $k_{\mathrm{sat}}, \mathrm{BC}, \mathrm{rs}_{\min }$, and depth modified simulations for the validation period showing higher errors in the agricultural area.

Three main considerations can be highlighted: (i) parameter change effect on RET is higher during summertime than during winter, with mean relative variation equal to $22.1 \%$ and $12.6 \%$ respectively; (ii) if only summer images are considered, relative variations during daytime are higher than during nighttime, with mean relative variation equal to $30.7 \%$ and $7.6 \%$, respectively; and (iii) this distributed analysis at basin scale confirms the results obtained at local scale (Fig. 1 and Fig. 2).

\section{2) VALidATION AGAinst GROUND Discharge MEASUREMENTS}

In Fig. 10 relative errors between observed and simulated volumes for each control cross section from the FEST-EWB run in the O-SoVeg configuration, $Q$ calibration, LST calibration, and combined LST and $Q$ calibration are shown. An improvement of model performance in terms of flood volume errors is obtained, confirming the results of the calibration phase with RE ranging between $-10 \%$ and $-1 \%$.

\section{Discussion and conclusions}

In this paper the calibration and validation of the soil and vegetation parameters in the distributed energy water balance model FEST-EWB for the upper Po River basin from 2000 to 2010 are analyzed using satellite land surface temperature and ground discharge data.

This work is a step forward in FEST-EWB calibration. In fact, previous studies (Rabuffetti et al. 2008; Pianosi and Ravazzani 2010) had as an objective the correct reproduction of streamflow along the main rivers network, which have been correctly estimated from the comparison with only observed $Q$ data. Instead, no estimate of evapotranspiration fluxes has been analyzed at basin scale.

The main suggestion of this study is that a combined calibration based on satellite land surface temperature and ground discharge data is needed to correctly reproduce not only volume discharge but also spatially distributed maps of RET and of evapotranspiration. Relative errors between observed and simulated volume show a general improvement between $-11 \%$ and $14 \%$ when the combined LST and $Q$ calibration is performed, and ET estimates are improved of $10 \%$.

These results confirm that the soil surface parameter calibration should be done with satellite LST when the evapotranspiration fluxes are the main simulation objective so that the correct spatial distribution of the energy and mass fluxes can be detected. Instead, discharge data are necessary if the entire hydrograph volume is the simulation target owing to the fact that the surface and hypodermic flow parameters are not controlled only by the superficial processes linked to LST. The traditional calibration based on ground discharge data in a few river sections lump the hydrological processes together so that the correct spatial determination of mass and energy fluxes cannot be reproduced. Instead, when a pixel to pixel calibration is performed, evapotranspiration can be better defined at pixel scale. The results found in this paper are in accordance with previous works that demonstrated the 
need of a multiobjective calibration based not only on local ground measurements but also distributed information. Among them, Crow et al. (2003) showed that a calibration based on discharge and land surface temperature improves the estimates of monthly evapotranspiration with respect to a calibration based only on discharge. Instead, Immerzeel and Droogers (2008) demonstrated that good results can be obtained if the calibration of a hydrological model is performed against evapotranspiration maps from a simplified energy balance model.

Moreover, FEST-EWB errors in terms of discharge as well of land surface temperature should be analyzed keeping in mind the general error linked to the observed data.

In fact, MODIS image uncertainty is mainly due to the retrieval algorithm, and definition of satellite LST over heterogeneous area should particularly be analyzed considering their spatial resolution, angle of view of the sensor, and emissivity (Kustas et al. 2004; Jacob et al. 2004; Soria and Sobrino 2007; Sobrino et al. 1994). Wang et al. (2008) report an extensive validation of different MODIS LST products with biases between $0.8^{\circ}$ and $3^{\circ} \mathrm{C}$ and RMSE around $2^{\circ} \mathrm{C}$.

Furthermore, problems arise also if discharge measurements are considered. In fact, it is well known from the literature that ground data of river flow are affected by high uncertainty (Di Baldassarre and Montanari 2009; Beven 2006). Pelletier (1988), after reviewing 140 publications on river discharge errors, found that the uncertainty ranges between $8 \%$ and $20 \%$. Di Baldassarre and Montanari (2009) highlighted that discharge errors along the Po River are between $6.2 \%$ and $42.8 \%$.

Acknowledgments. The authors thank ARPA Regione Piemonte (Italy) and ARPA Regione Lombardia (Italy) for providing the data used in this case study. This work was funded by the ACQWA EU/FP7 project (Grant 212250) "Assessing Climate Impacts on the Quantity and Quality of Water" and by Regione Lombardia in the framework of the PREGI project.

\section{REFERENCES}

Anderson, M. C., J. M. Norman, G. R. Diak, W. P. Kustas, and J. R. Mecikalski, 1997: A two-source time-integrated model for estimating surface fluxes using thermal infrared remote sensing. Remote Sens. Environ., 60, 195-216, doi:10.1016/ S0034-4257(96)00215-5.

_ A. Morse, and W. P. Kustas, 2012: Use of Landsat thermal imagery in monitoring evapotranspiration and managing water resources. Remote Sens. Environ., 122, 50-65, doi:10.1016/ j.rse.2011.08.025.

Bastiaanssen, W. G. M., M. Menenti, R. A. Feddes, and A. A. M. Holtslag, 1998: A remote sensing surface energy balance algorithm for land (SEBAL). 1. Formulation. J. Hydrol., 212-213, 198-212, doi:10.1016/S0022-1694(98)00253-4.

Beven, K. J., 2006: A manifesto for the equifinality thesis. J. Hydrol., 320, 18-36.

— , and A. Binley, 1992: The future of distributed models: Model calibration and uncertainty prediction. Hydrol. Processes, 6, 279-298, doi:10.1002/hyp.3360060305.

Brath, A., A. Montanari, and E. Toth, 2004: Analysis of the effects of different scenarios of historical data availability on the calibration of a spatially-distributed hydrological model. J. Hydrol., 291 (3-4), 232-253, doi:10.1016/ j.jhydrol.2003.12.044.

Cammalleri, C., G. Ciraolo, G. La Loggia, and A. Maltese, 2012: Daily evapotranspiration assessment by means of residual surface energy balance modeling: A critical analysis under a wide range of water availability. J. Hydrol., 452-453, 119 129, doi:10.1016/j.jhydrol.2012.05.042.

Caparrini, F., F. Castelli, and D. Entekhabi, 2004: Estimation of surface turbulent fluxes through assimilation of radiometric surface temperature sequences. J. Hydrometeor., 5, 145-159, doi:10.1175/1525-7541(2004)005<0145:EOSTFT >2.0.CO;2.

Castillo, V. M., A. Gomez-Plaza, and M. Martinez-Mena, 2003: The role of antecedent soil water content in the runoff response of semiarid catchments: A simulation approach. J. Hydrol., 284 (1-4), 114-130, doi:10.1016/S0022-1694(03)00264-6.

Corbari, C., G. Ravazzani, J. Martinelli, and M. Mancini, 2009: Elevation based correction of snow coverage retrieved from satellite images to improve model calibration. Hydrol. Earth Syst. Sci., 13, 639-649, doi:10.5194/hess-13-639-2009.

_ J. A. Sobrino, M. Mancini, and V. Hidalgo, 2010: Land surface temperature representativeness in a heterogeneous area through a distributed energy-water balance model and remote sensing data. Hydrol. Earth Syst. Sci., 14, 2141-2151, doi:10.5194/hess-14-2141-2010.

_- G. Ravazzani, and M. Mancini, 2011: A distributed thermodynamic model for energy and mass balance computation: FEST-EWB. Hydrol. Processes, 25, 1443-1452, doi:10.1002/ hyp.7910.

—, J. A. Sobrino, M. Mancini, and V. Hidalgo, 2013: Mass and energy flux estimates at different spatial resolutions in a heterogeneous area through a distributed energy-water balance model and remote-sensing data. Int. J. Remote Sens., 34 (9-10), 3208-3230, doi:10.1080/01431161.2012.716924.

Crow, W. T., and E. F. Wood, 2003: The assimilation of remotely sensed soil brightness temperature imagery into a land surface model using Ensemble Kalman filtering: A case study based on ESTAR measurements during SGP97. Adv. Water Resour., 26, 137-149, doi:10.1016/S0309-1708(02)00088-X.

,$- \ldots$, and M. Pan, 2003: Multiobjective calibration of land surface model evapotranspiration predictions using streamflow observations and spaceborne surface radiometric temperature retrievals. J. Geophys. Res., 108, 4725, doi:10.1029/ 2002JD003292.

— W. P. Kustas, and J. H. Prueger, 2008: Monitoring root-zone soil moisture through the assimilation of a thermal remote sensing-based soil moisture proxy into a water balance model. Remote Sens. Environ., 112, 1268-1281, doi:10.1016/ j.rse.2006.11.033.

Di Baldassarre, G., and A. Montanari, 2009: Uncertainty in river discharge observations: A quantitative analysis. Hydrol. Earth Syst. Sci., 13, 913-921, doi:10.5194/hess-13-913-2009.

Dooge, J. C. I., 1986: Looking for hydrologic laws. Water Resour. Res., 22, 46S-58S, doi:10.1029/WR022i09Sp0046S. 
Famiglietti, J. S., and E. F. Wood, 1994: Multiscale modelling of spatially variable water and energy balance processes. Water Resour. Res., 30, 3061-3078, doi:10.1029/94WR01498.

Fawcett, K. R., M. G. Anderson, P. D. Bates, J.-P. Jordan, and J. C. Bathhurst, 1995: The importance of internal validation in the assessment of physically based distributed models. Trans. Inst. Brit. Geogr., 20, 248-265, doi:10.2307/622435.

Franks, S. W., and K. J. Beven, 1999: Conditioning a multiple patch SVAT model using uncertain space-time estimates of surface fluxes as inferred from remotely sensed data. Water Resour. Res., 35, 2751-2761, doi:10.1029/1999WR900108.

$\longrightarrow,-$, P. F. Quinn, and I. R. Wright, 1997: On the sensitivity of soil-vegetation-atmosphere transfer (SVAT) schemes: Equifinality and the problem of robust calibration. Agric. For Meteor., 86 (1-2), 63-75.

Galleguillos, M., F. Jacob, L. Prévot, A. French, and P. Lagacherie, 2011: Comparison of two temperature differencing methods to estimate daily evapotranspiration over a Mediterranean vineyard watershed from ASTER data. Remote Sens. Environ., 115, 1326-1340, doi:10.1016/j.rse.2011.01.013.

Gupta, H. V., L. A. Bastidas, S. Sorooshian, W. J. Shuttleworth, and Z. L. Yang, 1999: Parameter estimation of a land surface scheme using multicriteria methods. J. Geophys. Res., 104 (D16), 19491-19503, doi:10.1029/1999JD900154.

Gutmann, E. D., and E. E. Small, 2010: A method for the determination of the hydraulic properties of soil from MODIS surface temperature for use in land surface models. Water Resour. Res., 46, W06520, doi:10.1029/2009WR008203.

Hain, C. R., J. R. Mecikalski, and M. C. Anderson, 2009: Retrieval of an available water-based soil moisture proxy from thermal infrared remote sensing. Part I: Methodology and validation. J. Hydrometeor., 10, 665-683, doi:10.1175/2008JHM1024.1.

Immerzeel, W. W., and P. Droogers, 2008: Calibration of a distributed hydrological model based on satellite evapotranspiration. J. Hydrol., 349, 411-424, doi:10.1016/j.jhydrol.2007.11.017.

Jacob, F., F. Petitcolin, T. Schmugge, E. Vermote, A. French, and K. Ogawa, 2004: Comparison of land surface emissivity and radiometric temperature derived from MODIS and ASTER sensors. Remote Sens. Environ., 90, 137-152, doi:10.1016/ j.rse.2003.11.015.

Jarvis, P. G., 1976: The interpretation of the variations in leaf water potential and stomatal conductance found in canopies in the field. Philos. Trans. Roy. Soc., B273, 593-610.

Jia, L., and Coauthors, 2003: Estimation of sensible heat flux using the Surface Energy Balance System (SEBS) and ATSR measurements. Phys. Chem. Earth, 28, 75-88, doi:10.1016/ S1474-7065(03)00009-3.

Kalma, J. D., T. R. McVicar, and M. F. McCabe, 2008: Estimating land surface evaporation: A review of methods using remotely sensed surface temperature data. Surv. Geophys., 29, 421-469, doi:10.1007/s10712-008-9037-z.

Kustas, W. P., F. Li, T. J. Jackson, J. H. Pruger, J. I. MacPherson, and M. Wolden, 2004: Effects of remote sensing pixel resolution on modeled energy flux variability of croplands in Iowa. Remote Sens. Environ., 92, 535-547, doi:10.1016/j.rse.2004.02.020.

Mancini, M., 1990: La modellazione distribuita della risposta idrologica: Effetti della variabilità spaziale e della scala di rappresentazione del fenomeno dell'assorbimento. Ph.D. dissertation, Politecnico di Milano, 127 pp.

Masseroni, D., G. Ravazzani, C. Corbari, and M. Mancini, 2012: Turbulence integral length and footprint dimension with reference to experimental data measured over maize cultivation in Po Valley, Italy. Atmósfera, 25, 183-198.
Minacapilli, M., and Coauthors, 2009: Estimation of actual evapotranspiration of Mediterranean perennial crops by means of remote-sensing based surface energy balance models. Hydrol. Earth Syst. Sci., 13, 1061-1074, doi:10.5194/ hess-13-1061-2009.

Montaldo, N., G. Ravazzani, and M. Mancini, 2007: On the prediction of the Toce alpine basin floods with distributed hydrologic models. Hydrol. Processes, 21, 608-621, doi:10.1002/ hyp.6260.

Mu, Q., M. Zhao, and S. W. Running, 2011: Improvements to a MODIS global terrestrial evapotranspiration algorithm. Remote Sens. Environ., 115, 1781-1800, doi:10.1016/j.rse.2011.02.019.

Myneni, R. B., and Coauthors, 2002: Global products of vegetation leaf area and fraction absorbed PAR from year one of MODIS data. Remote Sens. Environ., 83, 214-231, doi:10.1016/ S0034-4257(02)00074-3.

Nash, J. E., and J. V. Sutcliffe, 1970: River flow forecasting through the conceptual models part I-A discussion of principles. J. Hydrol., 10, 282-290, doi:10.1016/0022-1694(70)90255-6.

Noilhan, J., and S. Planton, 1989: A simple parameterization of land surface processes for meteorological models. Mon. Wea. Rev., 117, 536-549, doi:10.1175/ 1520-0493(1989)117<0536:ASPOLS >2.0.CO;2.

Norman, J. M., W. P. Kustas, and K. S. Humes, 1995: Source approach for estimating soil and vegetation energy fluxes in observations of directional radiometric surface temperature. Agric. For. Meteor., 77, 263-293, doi:10.1016/ 0168-1923(95)02265-Y.

Overgaard, J., D. Rosbjerg, and M. B. Butts, 2006: Land-surface modelling in hydrological perspective-A review. Biogeosciences, 3, 229-241, doi:10.5194/bg-3-229-2006.

Pan, M., E. F. Wood, R. Wójcik, and M. F. McCabe, 2008: Estimation of regional terrestrial water cycle using multi-sensor remote sensing observations and data assimilation. Remote Sens. Environ., 112, 1282-1294, doi:10.1016/j.rse.2007.02.039.

Pelletier, M. P., 1988: Uncertainties in the determination of river discharge: A literature review. Can. J. Civ. Eng., 15, 834-850, doi:10.1139/188-109.

Pianosi, F., and G. Ravazzani, 2010: Assessing rainfall-runoff models for the management of Lake Verbano. Hydrol. Processes, 24, 3195-3205, doi:10.1002/hyp.7745.

Rabuffetti, D., G. Ravazzani, C. Corbari, and M. Mancini, 2008: Verification of operational Quantitative Discharge Forecast (QDF) for a regional warning system-The AMPHORE case studies in the upper Po River. Nat. Hazards Earth Syst. Sci., 8, 161-173, doi:10.5194/nhess-8-161-2008.

Ravazzani, G., M. Mancini, I. Giudici, and P. Amadio, 2007: Effects of soil moisture parameterization on a real-time flood forecasting system based on rainfall thresholds. Quantification and Reduction of Predictive Uncertainty for Sustainable Water Resources Management, E. Boegh et al., Eds., IAHS Publ. 313, 407-416. D. Rametta, and M. Mancini, 2011: Macroscopic cellular automata for groundwater modelling: A first approach. Environ. Modell. Software, 26, 634-643, doi:10.1016/j.envsoft.2010.11.011.

Rawls, W. J., and D. L. Brakensiek, 1985: Prediction of Soil water properties for hydrologic modelling. Watershed Management in the Eighties, ASCE, 293-299.

Refsgaard, J. C., 1997: Parameterisation, calibration and validation of distributed hydrological models. J. Hydrol., 198, 69-97, doi:10.1016/S0022-1694(96)03329-X.

, and J. Knudsen, 1996: Operational validation and intercomparison of different types of hydrological models. Water Resour. Res., 32, 2189-2202, doi:10.1029/96WR00896. 
Roerink, G. J., Z. Su, and M. Menenti, 2000: S-SEBI: A simple remote sensing algorithm to estimate the surface energy balance. Phys. Chem. Earth, 25B, 147-157, doi:10.1016/ S1464-1909(99)00128-8.

Rosso, R., 1994: An introduction to spatially distributed modeling of basin response. Advances in Distributed Hydrology, R. Rosso et al., Eds., Water Resources Publications, 3-30.

Sobrino, J. A., Z. L. Li, M. P. Stoll, and F. Becker, 1994: Improvements in the split-window technique for land surface temperature determination. IEEE Geosci. Remote Sens. Lett., 32, 243-253, doi:10.1109/36.295038.

Soria, G., and J. A. Sobrino, 2007: ENVISAT/AATSR derived land surface temperature over a heterogeneous region. Remote Sens. Environ., 111, 409-422, doi:10.1016/j.rse.2007.03.017.

Su, Z., 2002: The Surface Energy Balance System (SEBS) for estimation of turbulent heat fluxes. Hydrol. Earth Syst. Sci., 6, 85-100, doi:10.5194/hess-6-85-2002.
Sun, S. F., 1982: Moisture and heat transport in a soil layer forced by atmospheric conditions. M.S. thesis, Dept. of Civil Engineering, University of Connecticut, $72 \mathrm{pp}$.

Thom, A. S., 1975: Momentum, mass and heat exchange of plant communities. Vegetation and Atmosphere, J. L. Monteith, Ed., Academic Press, 57-110.

Timmermans, W. J., and Coauthors, 2011: Estimation of the spatially distributed surface energy budget for AgriSAR 2006, part I: Remote sensing model intercomparison. IEEE J. Sel. Top. Appl. Earth. Obs. Remote Sens., 4, 465-481.

Verstraeten, W. W., F. Veroustraete, and J. Feyen, 2008: Assessment of evapotranspiration and soil moisture content across different scales of observation. Sensors, 8, 70-117, doi:10.3390/s8010070.

Wang, W., S. Liang, and T. Meyers, 2008: Validating MODIS land surface temperature products using long-term nighttime ground measurements. Remote Sens. Environ., 112, 623-635, doi:10.1016/j.rse.2007.05.024. 